\title{
Numerical simulations of progressive hardening by using ABAQUS FEA software
}

\author{
Tomasz Domańsk $i^{1,{ }^{*}, \text { Wiesława Piekarska }}{ }^{1}$, Marcin Kubiak $^{1}$, Zbigniew Saternus ${ }^{1}$, \\ Dorota Goszczyńska-Króliszewska ${ }^{1}$ \\ ${ }^{1}$ Institute of Mechanics and Machine Design Foundations, Czestochowa University of Technology, \\ Dabrowskiego 73, 42-200 Częstochowa, Poland, EU
}

\begin{abstract}
The paper concerns numerical simulations of progressive hardening include phase transformations in solid state of steel. Abaqus FEA software is used for numerical analysis of temperature field and phase transformations. Numerical subroutines, written in fortran programming language are used in computer simulations where models of the distribution of movable heat source, kinetics of phase transformations in solid state as well as thermal and structural strain are implemented. Model for evaluation of fractions of phases and their kinetics is based on continuous heating diagram and continuous cooling diagram. The numerical analysis of thermal fields, phase fractions and strain associated progressive hardening of elements made of steel were done.
\end{abstract}

Keywords: phase transformations, temperature fields, hardening

\section{Introduction}

The anticipation of final properties of the element that undergoes progressive hardening is possible after defining the type of the formed microstructure accompany thermal treatment. In order to achieve this aim it is essential to consider such a treatment of thermal phenomena, phase transformations and mechanical phenomena in numerical modeling. Phenomena that accompany thermal treatment are complex, and so far they are incompletely described. Findings of the numerical simulation of the above-mentioned phenomena depend on, inter alia, the accuracy of determination of phase transformation kinetics in the solid state. Surface hardening technology is very often used. There is no comprehensive numerical models which allow provide reliable assessment of phenomena that accompany to such a process of hardening. Progressive hardening is performed for concentrated heat sources with high power. Near to this sources occurs a high temperature and its considerable gradients $[1,2]$. Temperature and phase transformations in hardening steel elements are reasons to generated significant thermal and structural strains and in consequently to generate residual and temporal stresses.

\footnotetext{
* Corresponding author: domanski@imipkm.pcz.pl

Reviewers: Ján Vavro, Milan Žmindák
} 


\section{Model of thermal and mechanical phenomena}

Heat transfer equation with convective unit was used to modeling of thermal phenomena. The arguments of searched temperature fields are spatial coordinates (Lagrange's coordinates) and time $[3,4]$ :

$$
a \nabla^{2} T(\mathbf{x}, t)-\frac{\partial T(\mathbf{x}, t)}{\partial t}+\nabla T(\mathbf{x}, t) \cdot \mathbf{v}=-\frac{Q}{C}
$$

where: $T=T(\mathbf{x}, t)$ is temperature $[\mathrm{K}], a$ is thermal diffusivity, $C$ is specific heat capacity, $Q$ is element of volumetric heat sources that takes into account the heat generation from the source, $\mathbf{v}$ is the vector of velocity of the beam, $\mathbf{x}$ is the vector of position of considered particle (point), $t$ is time [s].

To have the possibility to carry out a full analysis of thermal treatment it is necessary to have proper mathematical and numerical models that can provide information about instantaneous temperature fields, the change in time of fractions of particular phase proportions of the material (Fig.1).

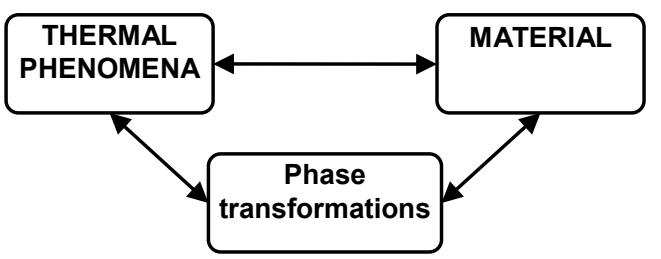

Fig. 1. Scheme of correlation of the hardening phenomena

Equation (1) is solved by methods proposed in [3]. Temperature distributions, obtained from the simulation after the determination of the heating process, are presented in Fig. 2.
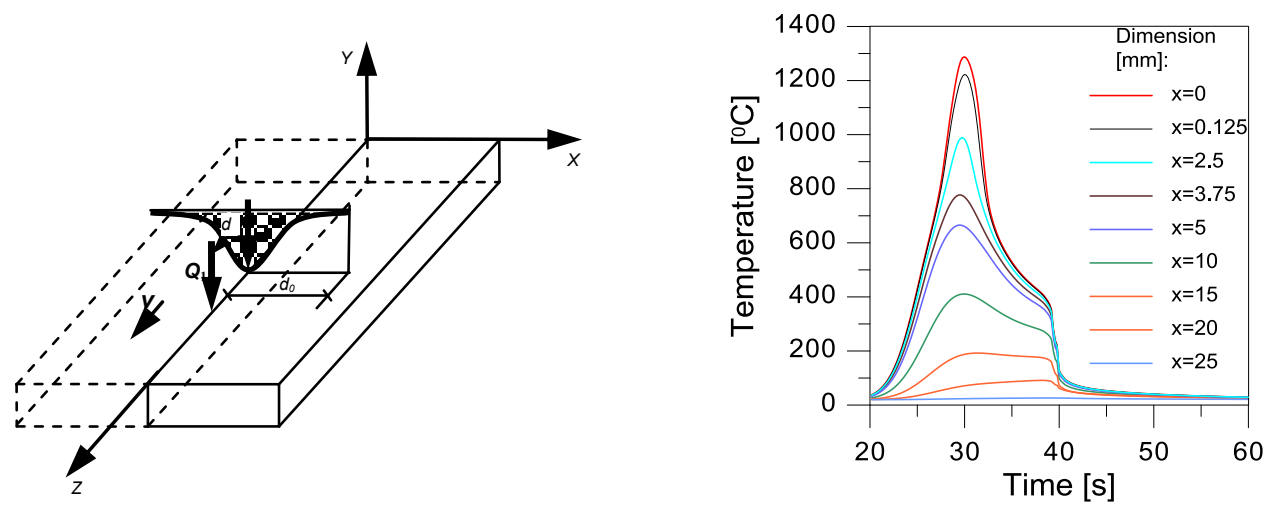

Fig. 2. Scheme of considered system, temperature distributions in $z=0$ the plane of operation of heat source

Two sources: first with a Gaussian distribution was heating source, and second at the distance $z=-d$ from the sprayed water stream. The distribution of second source has selected linear penetration $\left(x=x+d_{0}\right)$. Water was sprayed at a distance of $25 \mathrm{~mm}$ for the source of a heating source. Width at the sprayed water was $20 \mathrm{~mm}$. In an surface that was sprayed water cooling was carried out by the difference of temperature of the surrounding medium and the surface of the sample (condition Newton). 


$$
Q_{1}(\mathbf{x})=\frac{P(1-R)}{2 \pi r^{2}} \exp \left(-\frac{(x)^{2}+(z)^{2}}{2 r^{2}}-\beta|y|\right)
$$

where: $P$ is power derived from the heating source, $R$ is the reflectance, $\beta$ is absorption coefficient. $\mathrm{z}=\mathrm{z}_{0}+\mathrm{v} \cdot \mathrm{t}, \mathrm{z}_{0}$ is a central of heat source, $\mathrm{v}$ is speed of movement source, $\mathrm{t}$ is time. Fig. 1 shows the temperature distributions in time (thermal cycles) on the surface of hardened object along the x coordinate. While Fig. 3 has been represented the temperature distribution on the $\mathrm{x}$-axis perpendicular to the direction of the heating source.

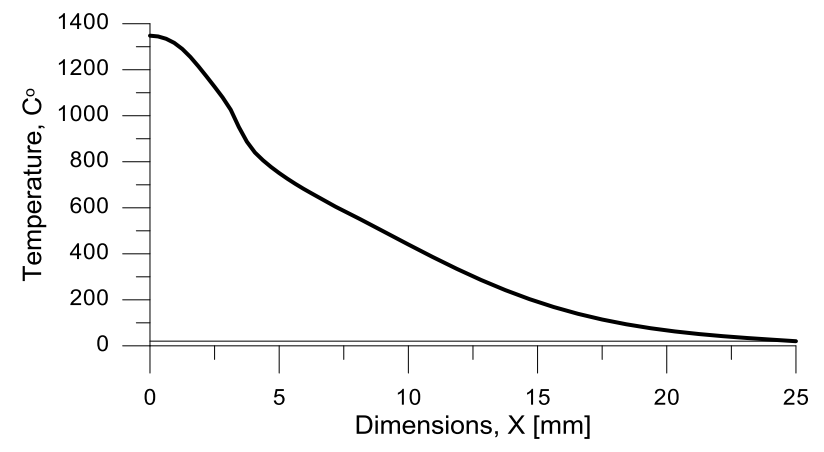

Fig. 3. Temperature distributions in $\mathrm{x}$ axis

The information about the stresses associated with hardening are obtained by solving the rate equilibrium equations, complemented by constitutive compounds and appropriate initial and boundary conditions. Young's modulus was depended on temperature. There are thus the opportunity to reflect changes of material constants of temperature and phase composition in the following increments of load $[3,5]$ :

$$
\begin{aligned}
\operatorname{div}(\dot{\boldsymbol{\sigma}}(\mathbf{x}, t)) & =0, \boldsymbol{\sigma}^{T}=\boldsymbol{\sigma}, \quad \dot{\boldsymbol{\sigma}}=\mathbf{E} \circ \dot{\boldsymbol{\varepsilon}}^{\mathrm{e}}+\dot{\mathbf{E}} \circ \boldsymbol{\varepsilon}^{\mathrm{e}}, \\
\boldsymbol{\sigma}\left(\mathbf{x}, t_{0}\right) & =\boldsymbol{\sigma}\left(\mathbf{x}, T_{k r}\right)=\mathbf{0}, \boldsymbol{\varepsilon}\left(\mathbf{x}, t_{0}\right)=\boldsymbol{\varepsilon}\left(\mathbf{x}, T_{k r}\right)=\mathbf{0}
\end{aligned}
$$

where: $\boldsymbol{\sigma}=\boldsymbol{\sigma}\left(\sigma_{\sigma \beta}\right)$ the stress tensor, $\mathbf{E}$ is the tensor of material constants, $\boldsymbol{\varepsilon}^{e}$ is the tensor of elastic strains $\left(\boldsymbol{\varepsilon}^{e}=\boldsymbol{\varepsilon}-\boldsymbol{\varepsilon}^{p}-\boldsymbol{\varepsilon}^{T P h}\right), \boldsymbol{\varepsilon}$ is a total strains tensor, $\boldsymbol{\varepsilon}^{p}$ plastic strains, $\boldsymbol{\varepsilon}^{T P h}$ is isotropic tensor of thermal strains and phase transformations $\left(\varepsilon^{T P h}=\varepsilon^{T}+\varepsilon^{P h}\right)$.

\section{Phase transformation is the solid state, structural and thermal strains}

Model the kinetics of phase transformations in the solid state on the base on continuous cooling diagram (CCT) for $\mathrm{C} 60$ carbon steel $[6,7]$. For determined heating and cooling rates austenitization temperatures $\left(\mathrm{A}_{\mathrm{c} 1}, \mathrm{~A}_{\mathrm{c} 3}\right)$ during heating, start $\left(\mathrm{F}_{\mathrm{s}}, \mathrm{P}_{\mathrm{s}}, \mathrm{B}_{\mathrm{s}}, \mathrm{M}_{\mathrm{s}}\right)$ and final temperatures $\left(\mathrm{F}_{\mathrm{f}}, \mathrm{P}_{\mathrm{f}}, \mathrm{B}_{\mathrm{f}}, \mathrm{M}_{\mathrm{f}}\right)$ of each phase transformation and final fractions of structure components during cooling are determined in UEXPAN subroutine. In this subroutine interpolated CHT and CCT diagrams are implemented with diagram of fractions of structural components (Fig. 4). 


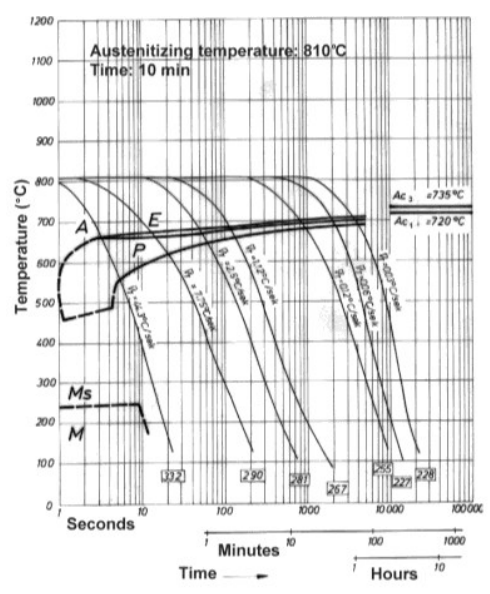

Fig. 4. Scheme of considered CCT diagrams

Phase fraction of austenite formed during heating is determined using a Machnienko model [7]. Phase fractions of the austenite during cooling process are determinated by temperature and cooling rate. Fraction of created phases such as bainite, ferrite and pearlite is also determinated by the model used for transformation of diffusion (Machnienko formula) taking account of the existing fractions of previously formed phases, ie.:

$$
\widetilde{\eta}_{A}(T, t)=1-\exp \left(-k \frac{T_{s A}-T}{T_{s A}-T_{f A}}\right), \quad \eta_{(\cdot)}(T, t)=\eta_{(\cdot)}^{\%} \widetilde{\eta}_{A}(1-\exp )\left(-k\left(\frac{T_{s}^{i}-T}{T_{s}^{i}-T_{f}^{i}}\right)\right)
$$

Transformation of austenite into martensite is defined as follows [2,7]:

$$
\tilde{\eta}_{M}(T)=\eta_{(\cdot)}^{\%} \tilde{\eta}_{A}\left(1-\exp \left(-k\left(\frac{M_{S}-T}{M_{s}-M_{f}}\right)^{m}\right)\right), T \in\left[M_{s}, M_{f}\right]
$$

where: $M_{s}$ and $M_{f}$ are receptively start and final temperatures of martensite transformation determined for specified cooling time in CCT diagram, while $k$ and $\mathrm{m}$ factors are determined experimentally [2].

Isotropic strains from the temperature and phase transformations (structural strains) are determined by formulas $[8,10]$ :

$$
d \varepsilon^{T P h}=\sum_{i=1}^{i=5} \alpha_{i} \eta_{i} d T-\varepsilon_{A}^{P h} d \eta_{A}, \quad d \varepsilon^{T P h}=\sum_{i=1}^{i=5} \alpha_{i} \eta_{i} d T+\sum_{j=2}^{j=5} \varepsilon_{j}^{P h} d \eta_{j}
$$

where: $i, j=A, B, F, M$. and $P, \alpha_{i}=\alpha_{i}(T)$ are thermal expansion coefficients of austenite, bainite, ferrite, martensite and pearlite, $\varepsilon_{i}^{P h}=\varepsilon_{i}^{P h}(T)$ are isotropic deformations of phase transformation: the initial structure in austenite, austenite in bainite, ferrite, martensite or in pearlite.

\section{Example}

Computer simulation of temperature field, phase fractions of progressive hardening process

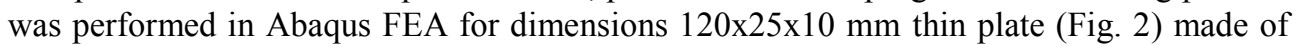
C60 steel with assumed base material structure consist of ferritic-pearlitic structure $(60 \%$ ferrite and $40 \%$ pearlite). Assumed in calculations hardening process parameters were set 
to: heat source power $\mathrm{Q}_{1}=1.45 \mathrm{~kW}$, beam radius $\mathrm{r}=10 \mathrm{~mm}$, and rate the heating source $\mathrm{v}=2,5 \mathrm{~mm} / \mathrm{s}$. In order to reduce computational time, symmetry of the joint was assumed in calculations. Calculated temperature field in the cross section (plane YZ) of the plate at the time $30[\mathrm{~s}]$, presented in Fig. 5, and in the cross section (plane XY) of the plate at the same time, presented in Fig. 6 allows the determination of heat affected zone geometry.

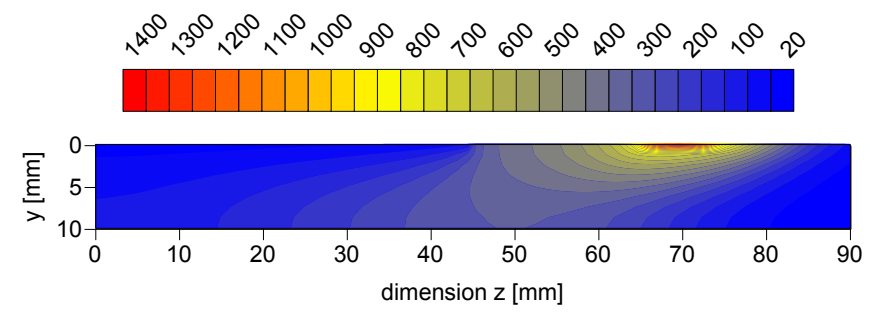

Fig. 5. Distributions (maps) of temperature (cross section YZ)
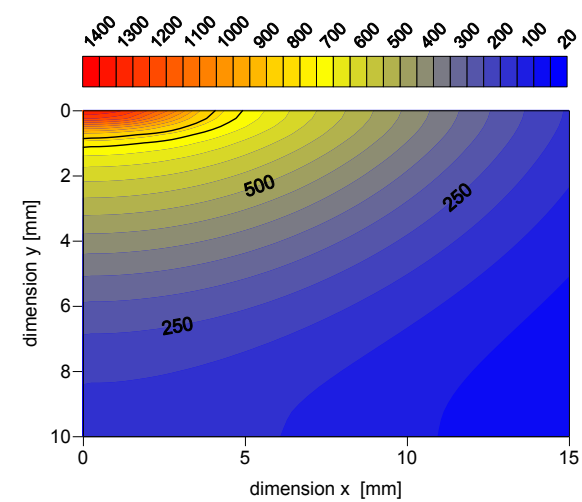

Fig. 6. Distributions (maps) of temperature (cross section YX)

Obtained distributions of phase fractions and kinetics of phase transformations from simulations (in cross section) are presented in Figure 7, and kinetics of phase transformations at point $\mathrm{x}=0$.
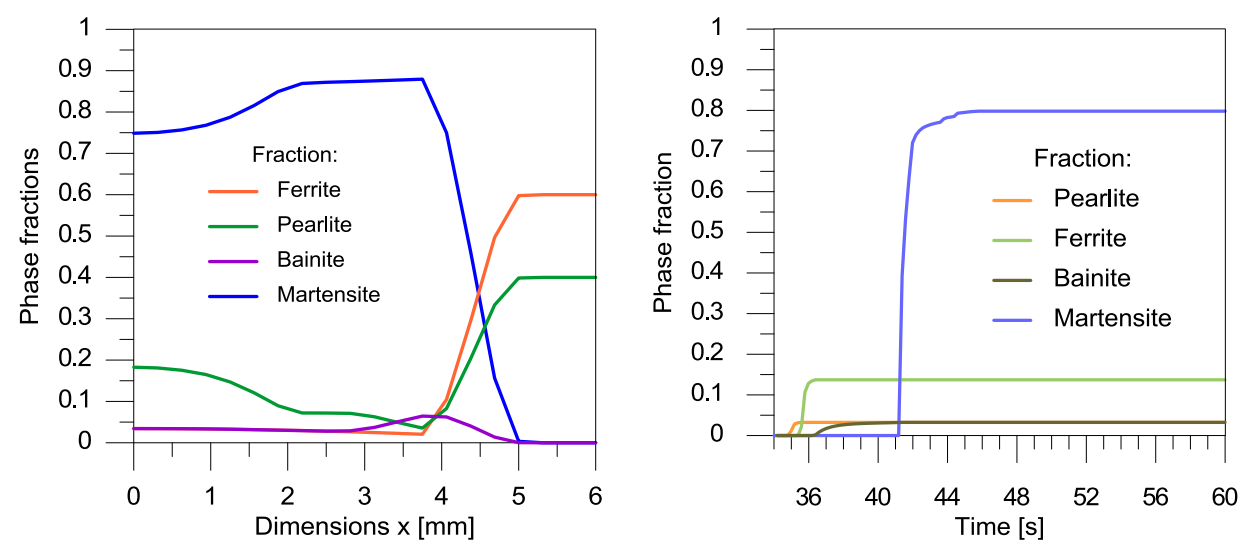

Fig. 7. Distributions of phase fractions in cross section, kinetics of phase transformations 


\section{Conclusions}

During the analysis of findings obtained from the simulation of progressive hardening of the steel object, which was heated by means of the movable heat source, one may observe that after the adoption of the heating and cooling method with respect to the hardened flat, the retained martensite, bainite, pearlite and ferrite, occur only in surface layers. Presented model for determination of movable heat source power distribution, kinetics of phase transformation, CHT and CCT diagrams, implemented in additional subroutines used in ABAQUS FEA allowed numerical simulation of progressive hardening process.

In the cross-section $\mathrm{YZ}$ and $\mathrm{YX}$ obtained temperature field (Fig.5,6) allows the determination of fusion zone and heat affected zone geometry. With so selected parameters heating source depth of hardened zone reaches about $2 \mathrm{~mm}$. In this zone behind the martensitic structure which has good mechanical properties. Developed in Abaqus FEA the $3 \mathrm{D}$ numerical model of hardening allows the prediction of joint structural composition. Estimated properties are helpful in determining a proper set of process parameters necessary to obtain desired geometry of object.

\section{References}

1. S. H. Kang, Y. T. Im, Three-dimensional thermo-elastic-plastic finite element modeling of quenching process of plain carbon steel in coulee with phase transformation. Journal of Materials Processing Technology 192-193, 381-390 (2007)

2. T. Domanski, A. Bokota, The numerical model prediction of phase components and stresses distributions in hardened tool steel for cold work. International Journal of Mechanical Sciences 96-97, 47-57 (2015)

3. O. C. Zienkiewicz, R. L. Taylor, The finite element method. (Butterworth-Heinemann, Fifth edition, vol. 1, 2, 3, 2000)

4. L. Huiping, Z. Guoqun, N. Shanting, H. Chuanzhen, FEM simulation of quenching process and experimental verification of simulation results. Material Science and Engineering A 452-453, 705-714 (2007)

5. W. Piekarska, M. Kubiak, M. Żmindak, Issues in numerical modeling of phase transformations in welded joint. Procedia Engineering 177, 141- 148 (2017)

6. T. Skrzypczak, E. Węgrzyn-Skrzypczak, Modeling of thermal contact through gap with the use of finite element method. J. Appl. Math. Comput. Mech. 14 (4), 145-152 (2015)

7. K. J. Lee, Characteristics of heat generation during transformation in carbon steel. Scripta Materialia 40, 735-742 (1999)

8. L. Sowa, P. Kwiaton, Numerical analysis of stress fields generated in the gantry crane beam. Procedia Engineering 177, 218-224 (2017)

9. D. Y. Ju, W. M. Zhang, Y. Zhang, Modeling and experimental verification of martensitic transformation plastic behavior in carbon steel for quenching process. Material Science and Engineering A 438-440, 246-250 (2006)

10. Z. Saternus, Computer Methods for Determination of Deformations in Welded Closed Profile. Procedia Engineering 177, 188 - 195 (2017) 